\title{
EMG, single fibre EMG and sacral reflexes in assessment of sacral nervous system lesions
}

\author{
DB VODUŠEK, M JANKO, J LOKAR \\ From the Institute for Clinical Neurophysiology, University Medical Centre, Ljubljana, Yugoslavia
}

SUMMARY EMG of pelvic floor muscles, single fibre EMG of external anal sphincter and both bulbocavernosus and anal reflexes were investigated in 31 men without sacral nervous system lesions and in 12 patients with neurogenic erectile impotence, of whom one had slight loss of sensitivity to pinprick in the lower sacral dermatomes. EMG and single fibre EMG abnormalities have been found concomitantly in eight patients and six of these had also prolonged bulbocavernosus reflex latencies. In two patients the prolonged bulbocavernosus reflex latency was the only abnormality. Single fibre EMG of anal sphincter muscle seems to be superfluous in routine evaluation of sacral nervous system lesions.

There is a need for objective and more detailed assessment of the sacral neuromuscular system in trauma and various nervous diseases, as well as in disorders of micturition, defaecation and potency. For this purpose electrophysiological methods have been used: EMG,${ }^{1-4}$ single fibre EMG ${ }^{5}$ pudendal nerve conduction measurement, ${ }^{67}$ and recording of bulbocavernosus $^{8}$ and anal $^{9}$ reflexes, but the respective usefulness and applicability of these methods in routine clinical evaluations is still far from established. This study reports the results obtained by recording EMG, single fibre EMG and bulbocavernosus and anal reflexes in a group of men with erectile impotence of supposed neurogenic basis, in order to judge the relative merits of the various methods in providing useful clinical information. Preliminary reports of the present study have been presented elsewhere. ${ }^{1011}$

\section{Subjects and methods}

The control group consisted of 31 men with a mean age of $26 \cdot 1$ years (17-46 years) without lesions of the sacral nervous system and without systemic disease. They were referred for neurophysiological evaluation because of premature ejaculation, enuresis (selected cases with normal results of a urodynamic evaluation) or pain problems.

The patient group consisted of 12 patients 22 to 45 years old who were referred with a diagnosis of probable neurogenic erectile impotence. They had a history of polyneuropathy (4 cases), lumbar disc disease (4 cases),

Address for reprint requests: David B Vodusek, MD, Zalośka 7, 61105 Ljubljama, Yugoslavia.

Received 17 June 1982

Accepted 9 August 1982 trauma to pelvis ( 2 cases) and diabetes mellitus ( 2 cases).

All subjects received a neurological examination. The electrophysiological recordings were made with a Medelec MS6 EMG apparatus, with standard concentric needle electrodes and single fibre EMG (SFEMG) electrodes (Medelec). The external urethral sphincter and external anal sphincter as well as the bulbocavernosus muscle were examined with the concentric needle by the percutaneous approach.' The bulbocavernosus and the anal reflex were evoked and detected as described by Ertekin and Reel ${ }^{8}$ and Pedersen et $a l^{9}$ respectively, with the exception that a bipolar surface electrode (Disa 13462) was used for stimulation of both reflexes.

With the SFEMG electrode the mean motor unit fibre density and the mean duration of multiple potentials were determined in the external anal sphincter, according to the standard criteria. ${ }^{12}$ The recordings were made from "tonically" active and reflexly activated motor units (talking to the patient, stroking his skin) and in a lesser degree from voluntarily activated motor units. In most cases only two skin penetrations were made at the lateral aspect of the orifice.

\section{Results}

The men from the control group were normal on neurological examination; their bulbocavernosus and anal reflexes were present. They reported good morning erections. The EMG recordings showed spontaneous background motor unit activity in sphincter muscles and electrical silence in the bulbocavernosus muscle on "relaxation". An interference pattern was obtained on voluntary and reflex activation. The amplitudes of motor unit potentials (MUPs) exceptionally exceeded $2 \mathrm{mV}$ and were never above $3 \mathrm{mV}$. Polyphasic potentials constituted up to $5 \%$ of MUPs in the 
Table 1 Single fibre EMG parameters in external anal sphincter muscle and sacral reflex latencies in 31 male subjects*

\begin{tabular}{|c|c|c|c|}
\hline & $\begin{array}{l}\text { Mean } \\
\text { value }\end{array}$ & $\begin{array}{l}\text { Standard } \\
\text { deviation }\end{array}$ & Range \\
\hline $\begin{array}{l}\text { Fibre density } \\
\text { Duration of complex }\end{array}$ & $1 \cdot 58$ & $0 \cdot 17$ & $1 \cdot 25-1 \cdot 90$ \\
\hline potentials (ms) & $1 \cdot 12$ & $0 \cdot 32$ & $0.54-1 \cdot 67$ \\
\hline $\begin{array}{l}\text { Mean interspike } \\
\text { interval (ms) } \\
\text { Bulbocavernosus }\end{array}$ & $0 \cdot 80$ & $0 \cdot 23$ & $0 \cdot 48-1 \cdot 48$ \\
\hline $\begin{array}{l}\text { Bulbocavernosus } \\
\text { reflex (ms) } \\
\text { Anal reflex (ms) }\end{array}$ & $\begin{array}{l}30 \cdot 8 \\
56 \cdot 8\end{array}$ & $\begin{array}{r}3 \cdot 72 \\
10 \cdot 96\end{array}$ & $\begin{array}{l}23-38 \\
38-83\end{array}$ \\
\hline
\end{tabular}

${ }^{*}$ Mean age $26 \cdot 1(\mathrm{SD}=6 \cdot 6$, range $17-46$ years $)$.

bulbocavernosus muscle, up to $10 \%$ of MUPs in the external urethral sphincter and up to $12 \%$ of MUPs in external anal sphincter. The SFEMG parameters and the bulbocavernosus and anal reflex latencies are given in table 1 . The calculated upper normal limit (mean value $+3 \mathrm{SD}$ ) for fibre density was 2 (muscle fibres/recording site), for the bulbocavernosus reflex latency $42 \mathrm{~ms}$ and for the anal reflex latency $89 \mathrm{~ms}$.

The men from the patient group suffering from polyneuropathy and lumbosacral disc disease had minor signs of their disease (absent Achilles tendon jerks and/or slight distal sensory loss in lower limbs). Only one patient had signs of a lesion in the lower portion of the sacral nervous system; this patient had a slight sensory loss to pinprick in the perineal region after pelvic trauma. All men from the patient group had bulbocavernosus and anal reflexes. Two patients reported good morning erections, nine reported poor morning erections and in one this information was not available. The results of EMG recordings were within the limits of the control group in four patients; in eight patients the interference pattern was reduced and the number of polyphasic potentials increased above $12 \%$ in at least one of the examined muscles. In five out of these eight patients MUPs with amplitudes above $3 \mathrm{mV}$ were recorded. Fibre densities in the external anal sphincters of patients ranged from 1.53 to $2 \cdot 57$; only the eight patients with EMG abnormalities had abnormal values for fibre density. Anal reflex latencies in the patient group ranged from 57 to $89 \mathrm{~ms}$ and bulbocavernosús reflex latencies ranged from 37 to $73 \mathrm{~ms}$; eight patients had abnormal bulbocavernosus reflex latencies. The interrelationship between the patients' diagnosis and electrophysiological findings is given in table 2 .

No patient with abnormalities of the neurophysiological parameters reported good morning erections.

In conclusion one out of 12 patients with probable (peripheral) neurogenic impotence had clinical signs of a lesion to the sacral portion of the nervous system and nine others (ten altogether) had neurophysiological signs of such a lesion.

\section{Discussion}

EMG of muscles whose innervation is supplied by sacral segments S2 to S4 the external sphincter muscles are the usual choice-is a time-honoured method $^{13}$ for evaluation of sacral nervous system lesions. ${ }^{1346}$ The presence of polyphasic potentials in sphincter muscles is slightly more pronounced than in limb muscles. ${ }^{3}$ In our control group polyphasic potentials were found most frequently in the external anal sphincter, which might be most exposed to stretch and thus to a lesion of intramuscular nerve twigs. The measurement of motor unit fibre density is a sensitive indicator of muscle fibre grouping ${ }^{12}$ and thus reflects the amount of reinnervation. Our values correspond well to those obtained by Neill and Swash ${ }^{5}$ who used the method for determination of a neurogenic basis for ano-rectal incontinence. However, they included muscle fibre potentials

Table 2 Neurophysiological findings in a group of 12 men with erectile impotence

\begin{tabular}{|c|c|c|c|c|}
\hline \multirow[t]{2}{*}{ Patient } & \multirow[t]{2}{*}{ Diagnosis } & \multicolumn{3}{|c|}{ Findings* } \\
\hline & & $E M G$ & $S F E M G$ & $\begin{array}{l}\text { Bulbocavernosus } \\
\text { reflex latency }\end{array}$ \\
\hline $\begin{array}{r}1 \\
2 \\
3 \\
4 \\
5 \\
6 \\
7 \\
8 \\
9 \\
10 \\
11 \\
12\end{array}$ & $\begin{array}{l}\text { Polyneuropathy } \\
\text { Polyneuropathy } \\
\text { Polyneuropathy } \\
\text { Polyneuropathy } \\
\text { Lumbosacral disc disease } \\
\text { Lumbosacral disc disease } \\
\text { Lumbosacral disc disease } \\
\text { Lumbosacral disc disease } \\
\text { Pelvic trauma } \\
\text { Pelvic trauma } \\
\text { Diabetes mellitus } \\
\text { Diabetes mellitus }\end{array}$ & $\begin{array}{l}\text { AB } \\
\text { AB } \\
\text { AB } \\
\text { AB } \\
\text { N } \\
\text { AB } \\
\text { AB } \\
\text { N } \\
\text { AB } \\
\text { AB } \\
\text { N } \\
\text { N }\end{array}$ & $\begin{array}{l}\text { AB } \\
\text { AB } \\
\text { AB } \\
\text { AB } \\
\text { N } \\
\text { AB } \\
\text { AB } \\
\text { N } \\
\text { AB } \\
\text { AB } \\
\text { N } \\
\text { N }\end{array}$ & $\begin{array}{l}\mathbf{A B} \\
\mathbf{A B} \\
\mathbf{A B} \\
\mathbf{N} \\
\mathbf{N} \\
\mathbf{A B} \\
\mathbf{N} \\
\mathbf{N} \\
\mathbf{A B} \\
\mathbf{A B} \\
\mathbf{A B} \\
\mathbf{A B}\end{array}$ \\
\hline
\end{tabular}

${ }^{*} \mathrm{~N}=$ within normal limits

$\mathrm{AB}=$ abnormal. 
above $150 \mu \mathrm{V}$ for their fibre density measurement, rather than the standard lower limit of $200 \mu \mathrm{V},{ }^{12}$ because the muscle fibre diameters in the external anal sphincter are smaller than in limb muscles. ${ }^{14}$ This should "increase" their fibre density as compared to our recordings based on standard criteria. The fibre density in the external anal sphincter in our control group is quite comparable to the values for limb muscles as obtained by Stålberg and Trontelj. ${ }^{12} \mathrm{We}$ would expect slightly higher fibre density values if the thinner muscle fibres in the external anal sphincter could be accounted for by changing the criteria of fibre density measurement, which would also then correlate better with the slightly increased polyphasia in the external anal sphincter. Certainly the average muscle fibre potential amplitude in the external anal sphincter is lower than in a limb muscle, as was observed by Neill and Swash ${ }^{5}$ and we found a relatively longer mean duration of complex potentials, as well as longer mean interspike intervals (table 1), which would suggest a slower conduction velocity in muscle fibres of smaller diameter. ${ }^{12}$ Motor unit fibre density measurement has in this admittedly small group of patients shown no obvious advantage over the standard EMG; it has also been tedious to assemble the needed number of recordings in some of the "abnormal" sphincters, even if the procedure is really neither difficult nor unusually painful in the normal subject. ${ }^{5}$

The latency of the sacral reflex response to electrical stimulation reflects mainly the conduction in the afferent and efferent limbs of the reflex arc and is thus an indicator of myelination and fibre diameter of these pathways. The EMG study on the other hand provides information about denervation and reinnervation of muscle fibres. Thus loss of axons associated with denervation or slowing of nerve conduction associated with demyelination could conceivably lead to abnormal findings in either EMG or the sacral reflex studies respectively; in this way findings in four of our patients (two with only abnormal EMG findings and two with only prolonged sacral reflex latencies-table 2) can be explained.

In conclusion, a concentric needle EMG examination of pelvic floor muscles with concomitant recording of electrically elicited muscle responses, especially the bulbocavernosus reflex, is recommended in the routine electrophysiological search for a lesion to the sacral nervous system. Single fibre EMG of the external anal sphincter is feasible but is primarily of value for research purposes; recordings with single fibre EMG needles have been rewarding in characterisation of pelvic floor muscles' response to electrical stimulation ${ }^{15}$ and in recordings of "tonic" motor units' activity in sphincter muscles. ${ }^{1016}$
This study was supported by the Research Committee of Slovenia, Ljubljama, Yugoslavia and Bob and Vivian Smith Foundation, Houston, Texas.

\section{References}

' Jesel M, Isch-Treussard C, Isch F. Electromyography of striated muscle of anal and urethral sphincters. In: Desmedt JE, ed. New Developments in Electromyography and Clinical Neurophysiology. Basel: Karger, 1973;2:406-20.

${ }^{2}$ Chantraine A. EMG examination of the anal and urethral sphincters. In: Desmedt JE, ed. New Developments in Electromyography and Clinical Neurophysiology. 1973;2:421-32.

${ }^{3}$ Allert ML, Jelasic F. Diagnostik neurogener Blasenstörungen durch Elektromyographie. Stuttgart: Thieme, 1974.

${ }^{4}$ Pedersen E. Electromyography of the sphincter muscles. In: Cobb WA, Van Duin $\mathrm{H}$, eds. Contemporary Clinical Neurophysiology 1978; EEG Suppl No 34:40516.

${ }^{5}$ Neill ME, Swash M. Increased motor unit fibre density in the external anal sphincter muscle in ano-rectal incontinence: a single fibre EMG study. $J$ Neurol Neurosurg Psychiatry 1980;43:343-7.

${ }^{6}$ Chantraine A, DeLeval J, Onkelinx A. Motor conduction velocity in the internal pudendal nerves. In: Desmedt JE, ed. New Developments in Electromyography and Clinical Neurophysiology. Basel: Karger, 1973;2:433-8.

${ }^{7}$ Jelasic F, Fischer D, Allert ML. Diagnosis of neurologic disorders of micturition without evidence of the pathological process by measuring conduction velocity of sacral roots. Urol Int 1975;30:100-2.

${ }^{8}$ Ertekin C, Reel F. Bulbocavernosus reflex in normal men and in patients with neurogenic bladder and/or impotence. J Neurol Sci 1976;28:1-15.

${ }^{9}$ Pedersen E, Harving H, Klemar B, Tørring J. Human anal reflexes. J Neurol Neurosurg Psychiatry 1978;41:813-8.

${ }^{10}$ Vodusek DB, Janko M. SFEMG in striated sphincter muscles. Abstracts of the II International single fiber EMG Symposium in Athens, Greece 1980. Muscle Nerve 1981;4:252.

1 Vodušek DB, Lokar J, Janko M. A study of neurophysiological methods for evaluation of erectile impotence. Zdrav Vestn 1981;50:703-7.

${ }^{12}$ Stålberg E, Trontelj JV. Single fibre electromyography. London: Mirvalle Press, 1979.

${ }^{13}$ Beck A. Elektromyographische Untersuchungen am Sphincter ani. Arch Physiol 1930;224:278-92.

${ }^{14}$ Beersiek F, Parks AG, Swash M. Pathogenesis of ano-rectal incontinence, a histometric study of the anal sphincter musculature. J Neurol Sci 1979;42:111-27.

15 Trontelj JV, Janko M, Godec C, Rakovec S, Trontelj M. Electrical Stimulation for Urinary Incontinence. Urol Int 1974;29:213-20.

${ }^{16}$ Vodusek DB, Kralj B. Change in sphincter EMG activity after strong electrical stimulation. Proceedings of the IX Annual Meeting of International Continence Society, Rome, Italy, 1979:235-8. 